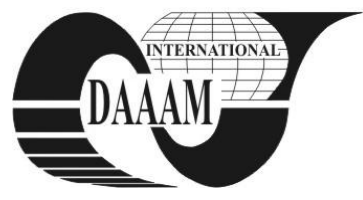

Annals of DAAAM for 2011 \& Proceedings of the 22nd International DAAAM Symposium, Volume 22, No. 1, ISSN 1726-9679 ISBN 978-3-901509-83-4, Editor B. Katalinic, Published by DAAAM International, Vienna, Austria, EU, 2011 Make Harmony between Technology and Nature, and Your Mind will Fly Free as a Bird Annals \& Proceedings of DAAAM International 2011

\title{
STATIC AND DYNAMIC CHARACTERISTICS OF ASYNCHRONOUS MOTOR
}

\section{RIECICIAROVA, E[va] \& NANASI, T[ibor]}

\begin{abstract}
The paper presents experimen-tal results and mathematical model of machine aggregates working under dynamic conditions. Generalized Kloss characteristics are derived for nominal operational speeds of 1,450 $\mathrm{min}^{-1}, 1,000 \mathrm{~min}^{1}$ and $720 \mathrm{~min}^{-1}$ under sinusoidal excitation. The steady-state motion presented as an ellipse centered at the working poin, which is intersection of moment characteristics of the asynchronous motor with the loading chara-teristics of DC motor with separate excitation. Measurements show, that it is necessary to consider the linear dynamic characteristics especially for dynamic response computations near to the resonance.
\end{abstract}

Key words: dynamic characteristics, dynamic testing, asynchronous motor, critical moment

\section{INTRODUCTION}

Experimental stand with the possibility of dynamic loading of machine aggregates and mechanisms (Fig. 1) enables to simula-te various cases of dynamic loading regi-mes with prescribed static and dynamic characteristics corresponding to production technological processes such as are the rolling, cutting, shearing, pressing, etc. The stand can be used for laboratory testing, production testing and examination, life testing and general tests of arbitrary me-chatronic system or of mechanical sub-systems as are the gears, couplings, clutches, shafts, motors, etc (Mudrik \& Nad 2008).

Another application is the investigation of energy and information flow through the electrical, pneumatic, hydraulic or mecha-nical subsystems of mechatronic system. Under mechatronic system we mean the integration of the electromechanical power subsystem with the electronic control subsystem to provide optimal regulation of the technological process or to provide optimal dynamic regime of the aggregate.

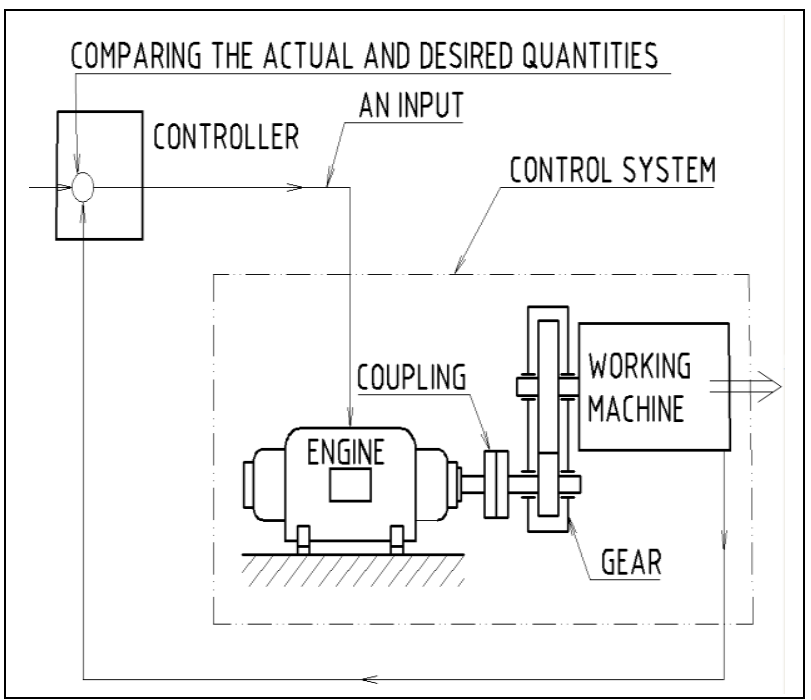

Fig. 1. Outline of the dynamic stand

\section{EXPERIMENTAL STAND}

Experimental stand for dynamic loading of machine aggregates enables to investigate the influence of parameters of the aggre-gate on unevenness of the angular velocity $\omega(t)$ or of the driving torque $M(t)$. Also it is possible to obtain the dynamic charac-teristics of the machine aggregate in steadystate or in transient regime in the form of relationship $M(\omega)$. The stand can help in assessment of capability of tested machine with respect to operational reliability, working accuracy and efficiency (Mudrik et al., 2008).

\section{STEADY-STATE UNDER PERIOD-IC LOAD}

Variation of parameters of aggregate (the inertia moment, fluctuating loads) gives rise to overall vibration, for which the unevenness of both the angular velocity and the driving torque is typical. As a result, the steady state appears in the form of the steady state motion.

The steady-state motion is characterised by closed trajectory of the form of an ellipse, depicted in detail on Fig. 2 together with it's characteristic points and with the corresponding linear static characteristics LSCH. Linear static characteristics is defined as tangent line at the working point $\Phi$.

\section{EXPERIMENTAL MEASUREMENT}

For analysis of dynamic properties of drives those properties are of importance, which influence the relations between input and output parameters of motor.

From measurement of the driving torque and of the slip (Table 1) the static moment characteristics of asynchronous motor was derived.

In general the static moment characteristics of asynchronous motor is described by the refined Kloss formula (Mudrik \& Nad 2007).

$$
M_{d}^{s}=\frac{2 M_{d k}\left(1-a s_{k}\right)}{\frac{s_{k}}{s}+\frac{s}{s_{k}}+2 a s_{k}},
$$

where: $s$ is the slip at the asynchronous speed,

$s_{k}$ is the critical slip corresponding to the critical moment $M_{d k}$,

$a$ is the ratio of working resistances of stator and rotor.

The relation (1) was used to compute the characteristics for experimental results under sinusoidal loading with following detailed properties: $n_{\mathrm{d}}=1000 \mathrm{~min}^{-1}$ (speed of asynchronous motor), $M_{\mathrm{dk}}=16.1 \mathrm{Nm}$ (maximum moment), $s_{\mathrm{k}}=0,23$ (critical slip) and $\mathrm{a}=0$ (ratio of working resis-tances of stator and rotor). 


\begin{tabular}{|c|c|c|c|}
\hline \multirow{2}{*}{ No. } & \multicolumn{3}{|c|}{$\mathrm{n}_{\mathrm{d}}=750\left[\mathrm{~min}^{-1}\right]$} \\
& $\mathrm{M}_{\mathrm{d}}[\mathrm{N} \mathrm{m}]$ & $\mathrm{n}_{\mathrm{d}}\left[\mathrm{min}^{-1}\right]$ & $\mathrm{s}$ \\
\hline 1 & 11,40 & 0 & 1 \\
\hline 2 & 12,10 & 75 & 0,90 \\
\hline 3 & 12,80 & 150 & 0,80 \\
\hline 4 & 13,70 & 225 & 0,70 \\
\hline 5 & 14,40 & 300 & 0,60 \\
\hline 6 & 15,10 & 375 & 0,50 \\
\hline 7 & 15,40 & 450 & 0,40 \\
\hline 8 & 15,50 & 465 & 0,38 \\
\hline 9 & 15,30 & 525 & 0,30 \\
\hline 10 & 13,90 & 600 & 0,20 \\
\hline 11 & 9,80 & 675 & 0,10 \\
\hline 12 & 6,80 & 712.5 & 0,05 \\
\hline 13 & 5,03 & 720 & 0,04 \\
\hline
\end{tabular}

Tab. 1. Measurement of static moment characteristics of asynchronous motor at speed $720 \mathrm{~min}^{-1}$

Using the above measured parameters allowed to find graphical presentation of the moment characteristics of asynchro-nous motor from Table 1 for rated revolutions $n_{d}=$ $720 \mathrm{~min}^{-1}$ as well as from Table 2 for measurement at speed $n_{d}=1450 \mathrm{~min}^{-1}$.

The characteristics for the speed $n_{d}=1000 \mathrm{~min}^{-1}$ was computed by the Kloss relation. In Fig. 3 all the three characteristics are compared.

The working point $P\left(\omega_{\phi}, M_{\phi}\right)$ is the centre of the ellipse, corresponding to steady state motion. The working point is given as inter-section of the moment characteristics of asynchronous motor $M_{d}\left(\omega_{d}\right)$ with the characteris-tics $M_{z}\left(\varphi_{z}, \omega_{z}\right)$ of the loading torque of the DC motor (Nad 2007)..

\begin{tabular}{|c|c|c|c|}
\hline \multirow{2}{*}{ No. } & \multicolumn{3}{|c|}{$\mathrm{n}_{\mathrm{d}}=1450\left[\mathrm{~min}^{-1}\right]$} \\
\cline { 2 - 4 } & $\mathrm{M}_{\mathrm{d}}[\mathrm{N} \mathrm{m}]$ & $\mathrm{n}_{\mathrm{d}}\left[\mathrm{min}^{-1}\right]$ & $\mathrm{s}$ \\
\hline 1 & 11.18 & 0 & 1 \\
\hline 2 & 11,85 & 75 & 0,95 \\
\hline 3 & 12,22 & 150 & 0,90 \\
\hline 4 & 12,64 & 225 & 0,85 \\
\hline 5 & 12,95 & 300 & 0,80 \\
\hline 6 & 13,58 & 375 & 0,75 \\
\hline 7 & 13,94 & 450 & 0,70 \\
\hline 8 & 14,25 & 525 & 0,65 \\
\hline 9 & 14,73 & 600 & 0,60 \\
\hline 10 & 15,15 & 675 & 0,55 \\
\hline 11 & 15,67 & 750 & 0,50 \\
\hline 12 & 16,13 & 825 & 0,45 \\
\hline 13 & 16,32 & 900 & 0,40 \\
\hline 14 & 16,51 & 975 & 0,35 \\
\hline 15 & 16,61 & 1050 & 0,30 \\
\hline 16 & 16,51 & 1125 & 0,25 \\
\hline 17 & 15,46 & 1200 & 0,20 \\
\hline 18 & 14,00 & 1275 & 0,15 \\
\hline 19 & 11,39 & 1350 & 0,10 \\
\hline 20 & 7,1 & 1425 & 0,05 \\
\hline
\end{tabular}

Tab. 2. Measurement of static moment characteristics of asynchronous motor at speed $1450 \mathrm{~min}^{-1}$

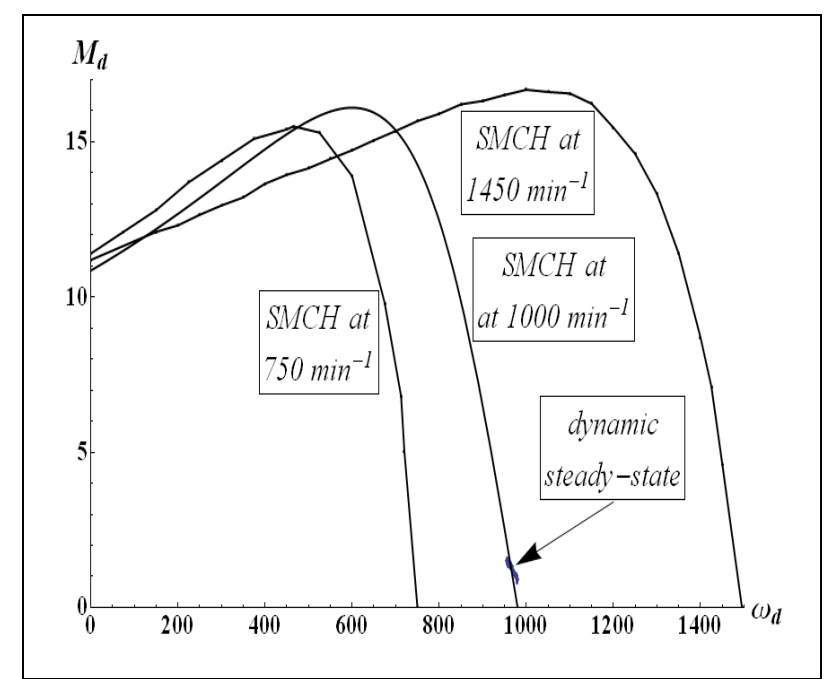

Fig. 2. Comparison of static moment characteristics

\section{CONCLUSION}

The inertia moment and fluctuating loads give rise to vibration of aggregates. Resulting from unevenness of both the angular velocity and the driving torque the steady state appears in the form of the steady state motion. Electro-mechanical moment and the corresponding slip are of periodic nature and the asynchronous motor operates at so called "dynamic steady state".

As no resonance is developed increasing the inertia moment, the static moment characteristics can be used for computations in case of aggregates with constant transmission ratio.

When the static characteristics is used in computations, than for low rotational speeds the computed amplitude of driving moment underestimates the real value and for high rotational speeds the computed amplitude overestimates the real value. Therefore at least for frequencies in the vicinity of possible resonance the linear dynamic characteristics should be used instead of the static characteristics.

\section{ACKNOWLEDGEMENTS}

The results and such way also the contribution came into existence in connection with MŠ SR grant support of the project VEGA - 1/0389/11.

\section{REFERENCES}

Mudrik, J., Nad', M. Principles of mecha-tronic modelling of machine aggregates. In Proceedings of International Conference ,Theory and Practice of Gear Drives and Transmissions", Iževsk, Russia, 2008, 27-32 (in Russian)

Mudrik, J. - Lipták, N. - Nad', M. The effect of the speed-torque characteristics upon the steady-state motion of the machi-ne aggregate. In Proceedings of the X. International Conference on the Theory of Machines and Mechanisms, Liberec, 2008, 417-422

Nad', M. Structural dynamic modifi-cation of vibrating systems. Applied and Computational Mechanics, 2007, 203-214

Oravcová, J., Mudrik, J. Contribution to dynamics of machine aggregates contain-ing gearing. Acta Mechanica Slovaca, TU Košice, 2008, 3, 317-324

Mudrik, J., Nad', M. Mechatronical ap-proach to machine dynamics. In Proceed-ings of $10^{\text {th }}$ International Symposium on Mechatronics. Alexander Dubček Univer-sity of Trenčín, Trenčianske Teplice, 2007, 33-38 